\title{
A CULTURA E A EDUCAÇÃo AMAZÔNICA NA ARTE DOS BRINQUEDOS DE MIRITI
}

\author{
Culture and Amazonic education in the art \\ OF MIRITI TOYS
}

\author{
Claudete do Socorro Quaresma da Silva \\ Mestranda em Educação - Universidade do Estado do Pará (UEPA) \\ Professora de Ensino Fundamental e Médio - SEDUC \\ Abaetetuba, PA - Brasil. \\ claudasilva2 I@gmail.com
}

\author{
Nazaré Cristina Carvalho \\ Doutora em Educação Física \\ Professora do Programa de Pós Graduação em Educação - PPGED/UEPA \\ Belém, PA - Brasil. \\ n_cris@uol.com.br
}

\begin{abstract}
Resumo: O presente trabalho versa sobre o brinquedo de miriti, um artesanato secular, tipicamente amazônico, por conter em suas formas elementos representativos do cotidiano ribeirinho. Apresenta as interfaces deste patrimônio imaterial e cultural do Estado do Pará com a cultura e a educação amazônica. Enfatiza os brinquedos de miriti como face da cultura amazônica que trazem em seu processo de feitura saberes e fazeres que há geraçôes se perpetua na regiấo através da oralidade e da observação. A cidade de Abaetetuba, no Estado do Pará, é o principal polo de confecção deste brinquedo. Este bem cultural tem presença marcante desde os primórdios na maior festividade religiosa do Brasil, o Círio de Nossa Senhora de Nazaré, em Belém, capital do Pará. Por fim, assinala que os artesáos do brinquedo de miriti com sua habilidade artística e sua forma singular de ensinar constroem a educaçáo na regiáo amazônica.
\end{abstract}

Palavras-chave: Arte. Brinquedos de miriti. Cultura e educaçáo amazônica.

ABstract: This paper is about the miriti toy, a secular craft, typically by Amazon contains in their forms elements representing everyday river. Display interfaces of this intangible heritage and culture of the State of Pará, with the Amazonian culture and education. Emphasizes the miriti toys such as the face of the Amazonian culture that bring in their process of making knowledge and practices that perpetuates itself for generations in the region through oral and observation. The city of Abaetetuba, State of Pará, is the main center of manufacture of this toy. This cultural property has a strong presence since the early days in the largest religious festival in Brazil, the Candle of Our Lady of Nazareth, Bethlehem, capital of Pará. Finally, the artisans who pointed toy miriti with his artistic ability and his unique way build education to teach in the Amazon region.

KeY words: Art. Culture and Amazonian education. Miriti toys. 


\section{Introduçáo}

Pretende-se neste artigo apresentar reflexóes iniciais acerca do objeto de pesquisa "brinquedos de miriti". Tal estudo está sendo realizado no mestrado em educaçấo da Universidade do Estado do Pará, na linha de pesquisa Saberes Culturais e Educação na Amazônia e tem como título "Brinquedos de Miriti: identidade e saberes cotidianos".

O miriti é uma palmeira característica da área de várzea, pertencente à flora amazônica. É muito conhecida e utilizada no Estado do Pará, principalmente no município de Abaetetuba. Dessa árvore o ribeirinho aproveita todas as partes para satisfazer suas necessidades cotidianas, da alimentação à expressão artístico-cultural, incluem-se, aqui, os brinquedos que são confeccionados da bucha do miriti.

Os brinquedos de miriti constituem uma forma inédita de expressar e representar o universo ribeirinho amazônico-paraense-abaetetubense. É um bem cultural da região Amazônica que enriquece a diversidade desse lugar. Legalmente é reconhecido como patrimônio imaterial e cultural do Estado do Pará.

O patrimônio imaterial é transmitido de geração em geração e ambiente, de sua interação com a natureza e de sua história, gerando um sentimento de identidade cultural e continuidade da criatividade humana. Esse processo se faz presente nos brinquedos de miriti.

Identificar e analisar os saberes que perpassam o processo de construção deste brinquedo e como este conhecimento vem sendo socializado há gerações por meio da oralidade e da observação é um dos objetivos da pesquisa. Propóe-se, ainda, identificar quais os principais aspectos da cultura são representados neste objeto analisando suas permanências e mudanças no decurso da história e relacionar as representaçóes materializadas nos brinquedos de miriti com o fortalecimento da identidade regional abaetetubense. Por intermédio das narrativas orais dos artesãos e da observação pretendemos atingir esses objetivos e apresentar as conclusôes na dissertação.

Neste artigo apresentam-se as interfaces da arte dos brinquedos de miriti com a cultura e a educação amazônico-abaetetubense. Estruturalmente o texto está organizado em três seções assim intitula- 
das: Brinquedos de miriti: as memórias de uma história; Brinquedos de miriti: de onde vem? Brinquedos de miriti, arte, cultura e educaçáo na Amazônia: interfaces.

\section{Brinquedos de miriti: as memórias de uma história}

$\mathrm{Na}$ história da humanidade o brinquedo está presente em todas as formas de organização social, política, econômica e cultural, sendo um elemento que produz momentos de prazer ao ser um instrumento de brincadeiras e de jogos muito utilizados na infância e, muitas vezes, estendendo-se até a idade adulta. Normalmente confeccionados por adultos, os brinquedos ao serem manuseados são transformados, sendo-lhes atribuídos significados diversos conforme flui o imaginário humano, principalmente o infantil a quem estes objetos são destinados. De acordo com o contexto em que estão inseridos, adultos e crianças constroem e reconstroem seus brinquedos, expressando através deles seu olhar acerca da realidade em que vivem e estabelecem suas relaçóes sociais.

Inicialmente os brinquedos eram produzidos manualmente. Com o processo de industrialização passaram a ser produzidos em larga escala para satisfazer as necessidades do mercado, estando diretamente ligado com a comercialização e a lucratividade.

Em termos culturais, os brinquedos industrializados atualmente predominam na sociedade ocidental e servem como instrumento de imposiçâo de valores, estilo e modo de vida de um grupo sobre outros. Todavia, apesar da sua hegemonia no mercado atual, em muitos lugares os brinquedos manuais continuam a existir. É o caso dos brinquedos de miriti da Amazônia.

Oliveira (I984, p. I8) destaca a importância do brinquedo artesanal na formação social das pessoas, considerando-os insubstituíveis por serem idealizados e confeccionados em sua totalidade pelo gênio criativo humano e não por máquinas. Diz este autor:

O fato de o brinquedo artesanal ainda se fazer presente numa sociedade dominada pela automação, e, mais recentemente, pela informática testemunha não só o conflito entre polos anta- 
gônicos, mas também representa a negação - realizada por artesãos amadores e profissionais - em deixar parecer não apenas brinquedos, mas fundamentalmente, um modo de se expressar no mundo: aquele que resulta da habilidade manual.

Assim, com uma estética singular figurada por cada artesão, os brinquedos artesanais, representam uma forma de resistência ao processo de globalização na medida em que, ao dominar todo o processo de produçáo do brinquedo, o artesão, com sua ação transformadora, rejeita a condição de mero reprodutor que lhe é concedida no interior da estrutura produtiva capitalista, para continuar como sujeito participante e construtor da cultura de sua comunidade e, consequentemente, agente colaborador da diversidade cultural do planeta.

Nessa direção, Nassar (1984, p. 5) ao referir-se aos brinquedos artesanais do Brasil, fala da existência de um "país submerso" que é ignorado pela oficialidade e aparente unidade imposta pelos padrôes culturais internacionais, mas que é real e se concretiza no cotidiano de várias localidades e comunidades, entre elas, na Amazônia-Pará, no município de Abaetetuba.

Confeccionados por artesãos e seus familiares, os brinquedos de miras. $\mathrm{O}$ marco histórico temporal, originário da feitura desses brinquedos, encontra-se perdido e disperso no tempo amazônico, todavia, achado e preservado na memória dos velhos ribeirinhos abaetetubenses que passam anos de suas vidas em contato com a palmeira, transfigurando-a com muita criatividade, cada parte que a compóe, nas inúmeras possibilidades de utilização, no sentido de suprir as necessidades do seu dia a dia.

Ecléa Bosi (1994, p. 82) sustenta que: "Um mundo social que possui uma riqueza e uma diversidade que náo conhecemos pode chegar-nos pela memória dos velhos. Momentos desse mundo perdido podem ser compreendidos por quem não os viveu e até humanizar o presente."

Apropriar-nos-emos da voz de duas caboclas ribeirinhas, com as quais conversamos e buscamos reencontrar nossas raízes culturais, para localizar historicamente este produto do miriti. Ao indagar sobre quando iniciou no município o uso da bucha do miriti para fazer brinquedos, em depoimento responderam: 
Já faz muito tempo, eu fazia desde a idade de I2 anos, eu fazia meus brinquedos de miriti tudinho, minhas bonecas. (Nina Abreu da Silva, artesã, 76 anos).

Eu digo que quando eu me entendi, com meus doze anos por aí assim, eu comecei a entender o que era o miriti, o papai ía pro mato cortava e tirava aquela tala que era pra nós fazer tupér, nós ía pra aula, [...], quando nós chegava cada uma de nós tinha que fazer um tupé pra ele, ele amarrava e ia vender, fazia peneira, fazia aricá ${ }^{2}$ da tala né, e do bagaço que a gente fazia o brinquedo. [...] meus filhos só brincavam com brinquedo de miriti, fazia aqueles barquinhos, olha a minha filha durante a vida dela até os I8 anos ela brincou com uma boneca só [...] só brincavam com brinquedo de miriti, até a sacola, hoje em dia é mochila, eles não, era caixa de miriti para por o livro deles, a lapiseira, tudinho. (Maria Pereira da Costa, professora, 86 anos).

Estas duas recordações expressam uma parte da história do caboclo abaetetubense que não está registrada nos documentos escritos, mas que é possível conhecê-la ouvindo aqueles que já viveram mais do que nós, os quais, por conseguinte, escutaram seus predecessores e assim sucessivamente. Dessa maneira concluímos que, pela oralidade, é possível construir e reconstruir a história de um povo.

$\mathrm{O}$ brinquedo de miriti ultrapassa os limites de Abaetetuba quando integra uma das faces culturais da maior celebração religiosa do Estado do Pará, o Círio de Nossa Senhora de Nazaré. Este ocorre anualmente na manhã do segundo domingo do mês de outubro nas ruas de Belém, capital do Estado.

Morais (1989) registra a presença do mencionado brinquedo no primeiro Círio de Nossa Senhora de Nazaré, no ano de I793, por ocasião de uma feira de produtos regionais dos municípios do Pará, sendo considerado, hoje, um dos elementos integrantes desta celebração religiosa marcante da identidade paraense que é tombada como patrimônio imaterial pelo Instituto do Patrimônio Histórico e Artístico Nacional (IPHAN). Na certidão de registro, assim aparece à relevância do brinquedo de miriti para o Círio: 
Assim foram destacados os seus elementos estruturantes-aqueles sem os quais o Círio não existiria- e identificadas às expressóes associadas à festa, em sua versáo contemporânea. Foram considerados elementos estruturantes dessa celebração: as procissôes da Transladação e do Círio, as imagens da santa, a original e a peregrina; a corda e a berlinda; o almoço do círio; o arraial; as alegorias do círio; a feira e os brinquedos de miriti; a cerimônia e a procissão do recírio. (IPHAN, 2004, p. 2).

Atualmente a feira do brinquedo de miriti permanece atrelada aos festejos da santa, ocorrendo anualmente na semana que antecede o Círio. Inclusive esses brinquedos continuam a peregrinar no Círio seja nas mãos de um promesseiro, nas girândolas dos artesãos ou nas mãos cuidadosas dos que querem brincar ou adornar sua moradia, da criança ao idoso, de qualquer modo é a nostalgia de sua leveza e o encantamento de suas cores que emprestam a alegria e a poesia na procissão.

Nos últimos anos os brinquedos de miriti ganharam visibilidade e produção em maior escala a partir do incentivo do poder público estadual e municipal resultando na organização e fundação da Associação dos Artesãos de Brinquedos e Artesanatos de Miriti de Abaetetuba (ASAMAB), em Fevereiro de 2003. A possibilidade de renda e trabalho em torno do artesanato de miriti despertou o interesse de geraçóes mais novas que se uniram e fundaram em dezembro de 2005 a "Miritong" (ONG do Miriti), desenvolvendo novos produtos e novas atividades.

Com o intuito de promover o brinquedo de miriti e demais produçóes locais, foi criado na cidade o festival do miriti, conhecido como "Miritifest", que teve sua primeira edição em abril de 2004. Tal evento movimenta a economia, ocasiáo em que possibilita a comercialização dos brinquedos, bem como de outros derivados do miriti, a exemplo das delícias culinárias. Além de proporcionar vasta programação cultural, com apresentaçôes de grupos folclóricos, escolha e premiação dos artesãos do ano, palestras ecológicas sobre a palmeira do miriti além de atividades esportivas.

O festival representa as tradiçôes populares do município de Abaetetuba e foi transformado em patrimônio cultural do Estado do Pará no ano de sua quinta edição, por meio da Lei Estadual no. 7.282, de 3 de julho de 2009 (PARÁ, 2009). Inserindo-se na categoria ofícios e modos 
de fazer do Manual de Aplicação do Inventário Nacional de Referências Culturais, elaborado pelo Departamento de Identificação e Documentação do IPHAN.

Assim, os artesãos dos brinquedos de miriti com seu ofício, seu saber tradicional e sua habilidade de fazer arte com a matéria prima miriti são sujeitos construtores da história da cultura e da educação amazônicaparaense-abaetetubense.

A localização deste bem cultural em meio à grande dimensão do espaço amazônico e à sua diversidade é o que abordaremos na seção seguinte.

\section{Brinquedos de miriti: de onde vem?}

"Eu venho desse reino generoso, onde os homens que nascem dos seus verdes continuam cativos, esquecidos e contudo, profundamente irmáos das coisas poderosas, permanentes como as águas, o vento e a esperança." (MELO, 2002, p. 28).

Historicamente conhecida por sua exuberância e riqueza natural e cultural a Amazônia guarda, em toda a sua extensão, uma biodiversidade que em parte, ainda é desconhecida tanto por seus habitantes quanto por visitantes e estudiosos. Da literatura dos cronistas viajantes que navegaram pelos rios amazônicos, a partir do século XVI, aos dados registrados por estudiosos e pesquisadores contemporâneos acerca da regiáo, revela-se a incomensurabilidade e o paradoxo que caracteriza este local. As palavras de Gondim (1994, p. 77; I38) são significativas nesse aspecto:

Os séculos podem variar e os cronistas serem originários das mais diferentes nacionalidades, no entanto diante do rio e da mata amazônicos, quase genericamente, nenhum se isentou de externalizar sentimentos que variavam do primitivismo préedênico ao infernismo primordial. Ainda, que familiarizados com a região ou mantendo o som frio e distanciado do pesquisador, esse objeto móvel, essa natureza grandiosamente avassaladora, em algum momento fez com que esses homens parassem e a escutassem, e a sentissem, muitas vezes deixando para 
trás olhares já estruturados, visóes já vividas, para pousarem os olhos renascidos na contemplação extasiada da grandiloqüência natural. [...] Para o estrangeiro, a Amazônia é a mescla do início e do fim, é o encontro dos opostos. Vem a ser, igualmente, o refúgio da insatisfação do homem diante de seus iguais.

No plano científico e geográfico as constatações e mensuraçóes, também, revelam a grandiosidade dessa regiáo: a bacia hidrográfica amazônica é a maior rede de rios do planeta Terra concentrando grande parte da água doce que existe e possui o maior rio do mundo em comprimento e volume de água, o Amazonas. A maior ilha fluvial do mundo localizase nesta região, a ilha do Marajó. É a mais extensa e rica floresta tropical do planeta, contendo inúmeras espécies vegetais, animais e minerais. Contempla, ainda, em seu vasto interior uma diversidade cultural que encanta por sua pluralidade, o que a torna singular.

Loureiro (2005, p.II) caracteriza a cultura amazônica como uma "diversidade diversa" graças à variedade cultural que compóe o espaço amazônico e identifica o caboclo amazônida. De norte a sul, de leste a oeste da região são expressóes artístico-culturais carregadas de signos e símbolos do cotidiano, a exemplo das lendas do boto e da cobra grande, entre tantas outras contadas e recontadas em cada canto deste lugar.

Neste espaço heterogêneo homens e mulheres, particularmente, caboclos ribeirinhos constroem e reconstroem dia a dia suas vidas. Convivendo numa relação direta com todos os elementos que fazem parte da natureza, produzem sua subsistência, extraindo da mata e do rio o alimento para o sustento de suas famílias, a matéria-prima para a construção das moradias e do principal meio de transporte - canoas e barcos -, bem como dos remédios para a cura das doenças e, ainda, inspiração para a criação artístico-cultural que se expressa através da música, do teatro, da dança, da poesia, do artesanato, dos brinquedos, enfim, de muitas formas simbólicas de expressão.

Essa relação de completude, respeito, saberes e fazeres se perpetua de uma geração a outra através da oralidade, sendo este um jeito de educar os filhos para a vida e educar-se conjuntamente, muito presente no cotidiano amazônico-ribeirinho. São conhecimentos não escolares sobre as plantas, os animais, o solo, os rios e a floresta seus benefícios e os cuidados 
essenciais para sua manutenção e preservação que são socializados e conduzem diariamente o ritmo e o estilo de vida das comunidades ribeirinhas.

Integrante deste universo, o caboclo paraense abaetetubense, artesão do brinquedo de miriti, externa seu olhar sobre o mundo e o seu espaço de relaçôes sociais de um modo bem peculiar que se soma à pluralidade e à singularidade regional.

Abaetetuba é uma cidade ribeirinha localizada no nordeste do Pará, banhada pelo rio Maratauíra (afluente do Rio Tocantins), distante IOI,5 $\mathrm{km}$ em linha reta da capital do Estado, Belém. De acordo com dados do Instituto Brasileiro de Geografia e Estatística (IBGE, 20Io) possui I.6Io,603 km² com I4I.IOo habitantes, sendo 58.102 residentes na zona rural (área de terra firme e ilhas) e 82.998 moradores da zona urbana, sede do município. Historicamente Abaetetuba foi fundada no século XVIII sendo elevada a categoria de cidade no dia is de agosto de 1895 .

No setor educacional vale destacar os saberes compartilhados, por meio da oralidade e da observação, pelos mais velhos aos mais novos em ambientes não escolares. Tais conhecimentos são tradicionais e perfazem vários aspectos da vida cotidiana cabocla abaetetubense. A exemplo dos estaleiros navais, das olarias, dos engenhos de fabricação de aguardente e das oficinas de brinquedo de miriti. São as escolas da vida que não aparecem nas estatísticas oficiais, mas que desempenham uma grande importância no processo educativo de homens e mulheres abaetetubenses.

Oficialmente Abaetetuba possui: 156 escolas de educação infantil, sendo I50 públicas municipais e 6 particulares; I4 escolas públicas estaduais de ensino fundamental, I68 municipais e 7 particulares; de ensino médio possui I Instituto Federal, I 4 estaduais e 3 particulares (IDESP, 20Io). Para ministrar o ensino superior e pós-graduação latu sensu, Abaetetuba conta com 2 campi federais (IFPA e UFPA) e diversos polos de universidades particulares.

O município possui uma beleza natural, própria do interior amazônico, beleza que pode ser visualizada no ir e vir das marés, que percorrem os inúmeros rios, igarapés e furos ${ }^{3}$ que circundam e adentram as ilhas e a cidade de Abaetetuba, formando verdadeiro labirinto. $\mathrm{Na}$ fauna podemos encontrar inúmeras espécies. A exuberante flora é caracterizada pela floresta de várzea. Em meio à multiplicidade natural encontra-se a palmeira, cientificamente denominada Mauritia flexuosa, popularmente 
chamada miriti. Palmeira esta, que faz parte do cotidiano das famílias ribeirinhas do Estado do Pará, especialmente dos habitantes do município Abaetetuba, na medida em que seu fruto alimenta, seu tronco serve de porto das palafitas, os braços da folhagem servem de matéria prima para a confecção de paneiros, cestas, hastes para papagaios, redes e os tão conhecidos brinquedos de miriti.

Confeccionados por inúmeros caboclos-artesãos, os brinquedos de miriti são a materialização das suas experiências vividas, seus olhares sobre o mundo em que vivem ao mesmo tempo em que encantam e alegram com seu colorido e leveza crianças, jovens e adultos. Loureiro (I995, p. 388) afirma que "[...] os brinquedos de miriti estâo impregnados de uma artisticidade singular [...]" na medida em que cada artesão esculpe seu objeto e exprime sua individualidade artística criadora, emprestando-lhe uma forma própria e única.

Abaetetuba constitui-se no principal centro, do Estado do Pará, de produção dos brinquedos de miriti, materializados na forma de barcos, canoas, cobras, tatus, casas, dançarinos, pássaros, peixes, entre tantas outras peças criadas, recriadas e produzidas pelos artesãos através das quais expressam o imaginário local. Este município mantem viva uma das fortes manifestaçóes da cultura popular por estar relacionado com o elemento lúdico e a sensibilidade infantil (BRASIL, I987).

\section{A arte nos brinquedos de miriti, cultura e educação: interlocuçóes.}

Diversos brinquedos eu já fiz, eu criei o ribeirinho, o pato do círio, o pinduca, a dança da garrafa, todos esses eu já fiz e, também, eu fiz um peru que era colocado pena por pena do peru tudo de miriti [...] eu criei um porta caneta que era uma abelha, abelha mestra e depois aí eu vou, cada tempo eu vou criando. O meu soca-soca é diferente dos outros [...] (Nina Abreu da Silva, artesã, 76 anos).

O patrimônio imaterial é transmitido de geração em geração e constantemente recriado pelas comunidades e grupos em função de seu 
ambiente, de sua interação com a natureza e de sua história, gerando um sentimento de identidade cultural e continuidade da criatividade humana. Oliveira (1984, p. I8), ao analisar os brinquedos artesanais, ressalta que nenhuma máquina é capaz de exprimir aquilo que somente através das mãos humanas é possível, isto é, nossa própria identidade.

$\mathrm{O}$ ato criador é único, livre de uniformidade, padronização, repetiçáo e caracteriza a singularidade do brinquedo de miriti, a identidade e a cultura de homens e mulheres ribeirinhos amazônico-paraenses-abaetetubenses. O depoimento reproduzido da artesã Nina Abreu é significativo nesses aspectos. E, ainda, observando as peças expostas para venda no VIII Festival do Miriti e na Feira do Círio, de 20II, notou-se a presença das tradicionais cobras, araras, botos, bem como o lançamento de vasos ornamentais, quadros de parede e alguns personagens televisivos, como Nemo, Toy story, todos confeccionados em miriti. Estes dados nos levam a uma análise inicial de indícios da criação e recriação, da incorporação de novos elementos presentes no cotidiano dos artesãos abaetetubenses, expressos na produção deste bem cultural. A continuidade da pesquisa nos possibilitará reflexôes mais consistentes.

Brougère (2oIo, p. 8) assinala que “[...] o brinquedo é dotado de um forte valor cultural, se definimos a cultura como o conjunto de significações produzidas pelo homem.”. Concordamos com este autor por entendermos que o brinquedo não é um objeto isolado do contexto no qual está inserido e muito menos está destituído de qualquer simbologia advinda das mãos ou das máquinas que o construiu. No brinquedo está manifesto o modo de ser, viver, pensar e fazer de homens e mulheres que, nas suas interaçōes sociais, criam e recriam formas de expressar, através da arte, sua existência no mundo.

Historicamente o uso e significação da palavra cultura passam por diferentes acepçóes. No século XX, o conceito de cultura foi incorporado aos estudos antropológicos e sociais passando a ser concebida como um conjunto de conhecimentos, crenças, arte, objetos, símbolos e significações construídos por seres humanos em suas interaçôes sociais. Brandão (2002, p. 22) quando trata do conceito de cultura assinala que

Somos o que criamos para efemeramente nos perpetuarmos e transformarmos a cada instante. Tudo aquilo que criamos a 
partir do que nos é dado, quando tomamos as coisas da natureza e as recriamos como os objetos e os utensílios da vida social, representa uma das múltiplas dimensóes daquilo que, em uma outra, chamamos de cultura.

Imerso nesse sentido de cultura localizamos o brinquedo de miriti, na medida em que este objeto náo possui uma forma única para as mais variadas aparências, bem como está cercado por um conjunto de experiências, valores, crenças, sentimentos, símbolos e significados que são historicamente vivenciados, construídos e partilhados cotidianamente por artesãos em suas relaçóes sociais.

Nessa direção o antropólogo Geertz (1989, p.I5) afirma que “[...] o homem é um animal amarrado a teias de significados que ele mesmo teceu [...]" considerando a cultura essas teias, assumindo, assim, uma concepção de cultura dinâmica que está em constante processo de recriação. Também, são relevantes as contribuiçōes de Alfredo Bosi (I992, p.I6) ao apresentar a cultura como "[...] o conjunto das práticas, das técnicas, dos símbolos e dos valores que se devem transmitir às novas geraçóes para garantir a reproduçáo de um estado de coexistência social [...]”. As análises dos citados autores convergem no sentido de aproximarem e promoverem o entrelaçamento da cultura com a educação, ponto que sustenta, teoricamente, nossa intenção de pesquisa ao concebermos o brinquedo de miriti como uma manifestação da cultura paraense que incorpora, em seu processo de construção, saberes que há geraçóes vem se perpetuando por meio da oralidade e da observação.

Os ribeirinhos confeccionam há séculos os brinquedos de miriti. Os moradores do município de Abaetetuba comumente ensinavam e ensinam a feitura do objeto por meio da observação (ainda que isso venha se modificando com a criação das associações de artesãos). São saberes transmitidos de pais para filhos, ao longo das geraçóes que são partes constitutivas da identidade cultural e histórica desses sujeitos. Assim como as águas de uma nascente são puro movimento cíclico, os saberes e fazeres do povo também são marcados pela circularidade, num ir e vir que, atravessando geraçóes, guardam o passado e gestam o futuro (Brasil, 2009). Nesse viés consideramos relevante a afirmação de Dias (2004, p. 92), em sua dissertação de mestrado conclui que 
Durante a observação do processo de construção do brinquedo do miriti e nas conversas com os artesãos e suas famílias, foi possível observar processos de aprendizagem, onde prevalece a afetividade na construção do conhecimento no cotidiano. [...] Adultos e crianças convivem num ambiente no qual a troca de saberes se dá a partir da observação, no olhar apurado, na oralidade sendo a escola a casa, o ateliê, a casa do vizinho que é artesão, é artista e sobretudo educador.

Estas análises nos apresentam sinais de que no processo de confecção do brinquedo de miriti circulam saberes entre geraçôes que tornam as oficinas de feitura desse objeto também espaços de aprendizagens, sendo que este fazer resulta na materialização de um produto que traz em seu conteúdo uma simbologia própria da cultura ribeirinha amazônica.

Brandão (I995, p. 7) mostra-nos perspectivas para reflexão ao afirmar que

Ninguém escapa da educação, em casa, na rua, na igreja ou na escola, de um modo ou de muitos todos nós envolvemos pedaços da vida com ela: para aprender, para ensinar, para aprendere-ensinar [...]. A educação existe onde não há a escola e por toda parte pode haver redes e estruturas sociais de transferência de saber de uma geração a outra.

Pensar a educação nesta ótica significa um alargamento da concepção dos processos educativos para além de um único cenário privilegiado de circulação do conhecimento e de realização de aprendizagens. $\mathrm{Ou}$ melhor, significa questionar e romper com a tradição historiográfica da educação brasileira a qual tem assentado seu foco de pesquisas e estudos somente em uma arena de saber, a escola, deixando à margem outros saberes e processos de aprendizagens que se encontram fora dos processos formativos de natureza escolar.

Tal perspectiva nos permite visualizar os espaços utilizados no processo de construção do brinquedo de miriti como lugares educativos de circulação de fazeres, saberes e aprendizagens. E nos aponta possibilidades de inserir no contexto acadêmico pesquisas acerca dos processos educati- 
vos não-escolares, no caso, aqueles que perpassam a confecção do brinquedo de miriti.

O reconhecimento da existência e relevância dos saberes populares dos amazônidas, particularmente do caboclo ribeirinho e dos indígenas, é pontuado pelo geógrafo-pesquisador Carlos Gonçalves, em sua obra Amazônia, amazônias (2005). Ao tratar da Amazônia náo como uma região homogênea, mas partindo da ótica da diversidade, nos mais variados aspectos, existente no interior desse espaço, Gonçalves (2005, p. 39) atenta para o fato de que

Qualquer engenheiro florestal, zoólogo, botânico, geógrafo ou geólogo sabe o quanto depende do conhecimento dessas populaçôes para realizar suas pesquisas, para identificar espécies animais e vegetais, conhecer seus hábitos. Muitos doutores sabem que suas teses deveriam partilhar a autoria com muitos caboclos da Amazônia.

São saberes que oficialmente estão exclusos da cultura escolar instituída, mas que se fazem presente ao serem estabelecidas essas interlocuçóes e na subjetividade de cada sujeito que participa desse ambiente institucionaliza-

\section{Consideraçóes finais}

Pesquisar e registrar os saberes populares que perpassam as manifestações artísticas culturais, suas formas de socialização entre geraçôes, desvelando as representaçóes, os signos e os símbolos que se fazem presente em tal expressão, no caso o brinquedo de miriti, constitui um desafio acadêmico. É desafiador na medida em que se desvincula da perspectiva de educação apenas no lócus escolar e considera os saberes que circulam no cotidiano de outros espaços sociais. E, também, por ter a memória e a ora- 
lidade como principais mananciais de informações, rompendo, assim, com a primazia das fontes escritas. Entretanto, acreditamos ser uma pesquisa realizável e relevante a ponto de ampliar as fontes na construção de uma epistemologia que tenha como premissa o reconhecimento da pluralidade cultural, o diálogo e a interação entre os fazeres e saberes construídos por todos os povos.

\section{Notas}

I Tupé: é um objeto confeccionado com a tala do miriti, utilizado para secagem ao sol de sementes de cacau, cupuaçu e outras frutas. É similar ao tapete.

2 Aricá: é um cesto confeccionado com a tala do miriti, muito utilizado pelos ribeirinhos na coleta e armazenamento do fruto do açaí.

3 Igarapés e furos são denominaçôes utilizadas na Amazônia para designar cursos de água caracterizados por pouca profundidade e por correrem quase no interior da mata. Braços estreitos de rios ou canais.

\section{Referências}

ASSOCIAÇÃO DOS ARTESÃOS DE BRINQUEDOS E ARTESANATOS DE

MIRITI DE ABAETETUBA. Estatuto. Abaetetuba, 2003. . PROJETO VIII MIRITIFEST, $201 \mathrm{I}$.

BOSI, Alfredo. Dialética da colonização. São Paulo: Companhia das Letras, I992.

BOSI, Ecléa. Memória e sociedade: lembrança de velho. 3. ed. São Paulo: Companhia de letras, I994.

BRANDÃO, Carlos Rodrigues. O que é educação? São Paulo: Brasiliense, 1995. . A educação como cultura. Campinas, São Paulo: Mercado das Letras, 2002.

BRASIL, Governo Federal do. Curriculo, conhecimento e cultura. Ano XIX, No I, abr. 2009.

. Ministério da Cultura. O brinquedo no círio de Belém. Brasília, DF, 1987.

BROUGÈrE, Gilles. Brinquedo e cultura. 8. ed. São Paulo: Cortez, 20 o.

DIAS, Josiane de Almeida. Representaçóes sociais na construção do brinquedo de miriti: uma manifestação da motricidade humana. Dissertação (Mestrado em Motricidade Humana)- Universidade do Estado do Pará, Belém, 2004. 
GEERTZ, Clifford. A interpretação das culturas. Rio de Janeiro: Guanabara Koogan, I989.

GONÇALVES, Carlos W. P. Amazônia, amazônias. 2. ed. São Paulo: Contexto, 2005.

GONDIM, Neide. A invenção da Amazônia. São Paulo: Marco Zero, I994.

INSTITUTO BRASILEIRO DE GEOGRAFIA E ESTATÍSTICA. Banco de Dados. Disponível em: http://www.ibge.gov.br/ . Acesso em: 22 maio 20 I.

INSTITUTO DE DESENVOLVIMENTO ECONÔMICO, SOCIAL E

AMBIENTAL DO PARÁ. Estatística municipal. Disponível em: http://www.sie.pa.gov. brl. Acesso em: I $^{\circ}$ ago. $201 \mathrm{I}$

INSTITUTO DO PATRIMÔNIO HISTÓRICO E ARTÍSTICO NACIONAL. Certidão de Registro no livro das celebraçôes dos bens imateriais. Brasília, DF: 2004.

LOUREIRO, João de J. P. Cultura amazônica: uma poética do imaginário. Belém: Cejup, I995.

. Cultura amazônica uma diversidade diversa. In: UNIVERSIDADE

FEDERAL DO PARÁ. Série Aula Magna, no 2. mar. 2005.

MELLO, Thiago de. Amazonas, pátria da água. Rio de Janeiro: Bertrand Brasil, 2002.

MORAIS, Luiz Carlos. Aprendendo com o brinquedo popular na arte com o miriti: um estudo do brinquedo popular, através de seus elementos fundamentais aplicados na educação. Belém: SECULT/FCPTN, 1989.

NASSAR, Emmanuel (Coord.). Brinquedos populares. Cadernos de Cultura, estudos 2. Belém: Falangola, 1984.

OLIVEIRA, Paulo de S. O que é brinquedo? Brasiliense. 1984. (Primeiros Passos). Brinquedos artesanais e expressividade. São Paulo: SESC-CELAZER, I982.

PARÁ. Lei estadual No. 7.282, de 3 de julho de 2009. Declara o MIRITIFEST como Patrimônio Histórico do Estado do Pará. In: Diário Oficial do Estado do Pará, Belém, ano CXIX, n' 3 I. 453 , de 3 jul. 2009.

Recebido em Io mar. 20I2 / Aprovado em 24 abr. 2012

Para referenciar este texto

SILVA, C. S. Q.; CARVALHO, N. C. A cultura e a educação amazônica na arte dos brinquedos de miriti. EccoS, São Paulo, n. 27, p. I7-32. jan./abr. 2012. 